\title{
KAJIAN TEKNIK SEARCH ENGINE OPTIMIZATION PADA WEBSITE SEBAGAI STRATEGI PEMASARAN DI INTERNET
}

\author{
Dwi Mandasari Rahayu ', Agung Budi Prasetyo ${ }^{2}$ \\ ${ }^{1}$ Prodi Teknologi Rekayasa Multimedia, Jurusan Desain, Politeknik Negeri Media Kreatif \\ ${ }^{2}$ Prodi Teknologi Rekayasa Multimedia, Jurusan Desain, Politeknik Negeri Media Kreatif \\ Korespondensi: Jalan Srengseng Sawah, Jagakarsa, Jakarta Selatan \\ Surel: ${ }^{1}$ dwimandasarirahayu@gmail.com; ${ }^{2}$ agung@polimedia.ac.id
}

\section{INFO ARTIKEL}

\section{Sejarah Artikel:}

Diterima: 05/02/20

Direvisi: 20/05/20

Dipublikasikan: 31/05/20

e-ISSN: 2721-0995

p-ISSN: 2721-9046

Kata Kunci:

SEO, Website, Strategi

Pemasaran, Internet,

Google

Keywords:

SEO, Website, Online

Marketing, Google, Search

Engine Tools

\begin{abstract}
A B STRAK
Kajian Teknik Search Engine Optimization pada Website sebagai Strategi Pemasaran di Internet. Penelitian ini membahas tentang optimalisasi teknologi internet dalam strategi pemasaran. Pemanfaatan teknologi internet untuk pemasaran baik produk maupun jasa sudah bergeser ke media digital. Target pasar yang mencakup lintas negara dan sifatnya yang mampu daring selama 24 jam menjadi kekuatan utama pemasaran digital. Terlebih, biaya promosi di internet sebagai media pemasaran relatif lebih murah jika dibandingkan dengan media konvensional seperti televisi, radio, koran, dan lainnya. Perlu strategi dan metode yang tepat agar website banyak dikunjungi oleh pengguna internet. Website yang dijadikan sebagai media pemasaran harus dibangun dengan kaidah yang benar, sehingga bisa menjadi media pemasaran yang optimal. Salah satu kaidah yang baik dalam membangun situs internet sebagai media pemasaran adalah mengoptimasi website agar terindeks dengan baik di mesin pencari seperti Google. Metode penelitian ini adalah observasi secara on-page dan off-page terhadap website. Hasilnya, website yang dianalisis telah memenuhi kaidah pemasaran berdasarkan SEO tetapi ada beberapa hal yang masih dapat dikembangkan.
\end{abstract}

\section{ABSTRACT}

The Study of Search Engine Optimization on Website as A Marketing Strategy on the Internet. The Internet usages have been growing. The marketing ways for both products and services have changed into the internet media. Cross-country target market and 24-hour services become the main strengths of online marketing. Moreover, the cost of promotion on the internet marketing is more effective than conventional media such as television, radio, and newspapers. It needs some right strategies and methods to get many visitors. The websites used as marketing media must be built with the right rules to become the optimum internet marketing. One of the rules to build internet marketing is optimizing website to be indexed properly in search engines like Google. This research method is on-page and off-page observation of web pages. Consequently, the analyzed web pages have met the marketing rules based on SEO. However, many other aspects still need improvement. 


\section{PENDAHULUAN}

Jumlah penduduk Indonesia pada 2017 mencapai 262 juta orang. Menurut laporan Asosiasi Penyelenggara Jasa Internet Indonesia (APJII), sekitar 143 juta orang atau lebih dari 50\% jumlah penduduk Indonesia telah terhubung jaringan internet sepanjang 2017. Mayoritas pengguna internet yakni sebanyak $72,41 \%$ masih dari kalangan masyarakat urban. Pemanfaatannya bukan hanya untuk berkomunikasi tetapi juga untuk membeli barang, memesan transportasi, hingga berbisnis dan berkarya. Angka tersebut merupakan potensi luar biasa mengingat jumlah penduduk Indonesia mencapai 262 juta jiwa dan merupakan populasi yang sangat besar bila dibandingkan dengan penetrasi internet di negara-negara sekitar Indonesia, baik di Asia maupun Australia (MarkPlus, 2012).

Search Engine Optimize (SEO) sangat penting dalam internet marketing. Banyak yang mengira bahwa membuat website saja sudah cukup untuk mengembangkan dan membangun bisnis secara daring. Akan tetapi, pada kenyataannya tidak demikian. Setelah membuat website, ada banyak hal yang harus dilakukan oleh seseorang agar lamannya banyak dikunjungi atau trafiknya meningkat. Jika trafik meningkat maka potensi produk atau jasa terjual akan turut meningkat. Keuntungan dari bisnis daring hanya dapat diraih apabila website yang dimiliki banyak pengunjungnya. Langkah selanjutnya yang harus dilakukan adalah meningkatkan jumlah pengunjung menggunakan SEO.

\section{TINJAUAN PUSTAKA}

\section{Internet Marketing}

Internet Marketing adalah proses memasarkan produk dan layanan kepada pelanggan dengan menggunakan media website. Promosi, iklan, transaksi dan pembayaran dapat dilakukan melalui website. Pengguna internet marketing dapat dengan mudah mengakses informasi di mana saja dengan komputer yang terhubung ke internet (Blythe, 2005).

Ada tiga prinsip dasar dari internet marketing, yaitu: immediacy, personalization, dan relevance. Immediacy adalah perubahan yang cepat dan up to date dalam waktu per menit termasuk kecepatan pengelola website menanggapi secara daring. Personalization adalah pelanggan harus ditanggapi dan dilayani secara personal tidak lagi sama untuk semua pelanggan. Gunakan informasi pribadi secara daring yang dimasukkan pelanggan sebagai keuntungan perusahaan. Relevance adalah komunikasi daring harus dibuat menarik agar pelanggan merasa dilayani sehingga membuat pelanggan merasa nyaman (Fang dan Ting, 2006).

Perbedaan internet marketing dengan pemasaran tradisional adalah bahwa internet marketing lebih masuk akal, lebih murah, cepat, menjangkau banyak pelanggan sehingga menjadi cara terbaik bagi bisnis yang ingin memasuki pasar baik lokal maupun internasional (Hanieh, 2012). 


\section{Search Engine Optimization}

Istilah SEO bukan lagi menjadi hal yang asing karena sudah sering didengar dan dibaca. Bahkan, sudah mulai dipraktikkan secara konsisten untuk mempromosikan website. Namun, mungkin bagi sebagian pembaca, SEO masih menjadi istilah yang asing dan bisa jadi baru pertama didengar. Jadi sederhananya, SEO merupakan teknik dan strategi yang diterapkan pada website agar sering muncul pada halaman pertama mesin pencari. Misalnya, usaha tentang jasa kontraktor, ketika seorang pengguna internet mengetik kata tersebut di mesin pencari, lalu website tersebut muncul di halaman pertama mesin pencarian seperti Google.

Secara teoretis, SEO adalah serangkaian proses sistematis yang bertujuan untuk meningkatkan volume dan kualitas trafik kunjungan melalui mesin pencari dengan memanfaatkan mekanisme kerja algoritma mesin pencari tersebut. Tujuan dari SEO adalah menempatkan sebuah website pada posisi atas dari hasil pencarian berdasarkan kata kunci tertentu yang ditargetkan. Secara logis, situs web yang menempati posisi teratas pada hasil pencarian akan memiliki peluang yang lebih besar untuk mendapatkan pengunjung (Nova, 2013).

Jika website selalu berada di halaman pertama mesin pencari untuk banyak frasa yang terkait dengan produk dan jasa yang ditawarkan, maka pengunjung website akan ramai. Terlebih lagi, jika pemilik dan penawaran untuk konsumen menarik, maka bukan tidak mungkin penjualan turut meningkat. SEO ini tentunya tidak bisa diimplementasikan secara langsung. Maka dari itu, dibutuhkan waktu yang relatif panjang untuk mengaplikasikan SEO. Teknik SEO dapat dilakukan baik secara mandiri maupun bekerjasama dengan perusahaan Jasa SEO profesional. Semakin banyak pengunjung website, maka semakin besar peluang penjualan dari website tersebut.

\section{Istilah dalam SEO}

Terdapat beberapa istilah penting yang sering digunakan dalam dunia SEO, seperti yang terdapat dipaparkan Davies (2020) pada Beanstalk Internet Marketing, yaitu:

1. Algoritma

Sebuah rumus matematika yang digunakan oleh mesin pencari untuk menentukan peringkat sebuah halaman web dalam hasil pencarian.

2. Anchor Text

Text yang terlihat dalam hyperlink. Jika diklik link tersebut dapat memudahkan penelusuran menuju ke halaman web lain. Istilah ini juga dikenal sebagai Link Text.

3. ALT Tag

Text yang muncul saat pengguna menggeser kursor ke arah gambar, grafis, atau ketika gambar berubah menjadi "off" pada browser.

4. Back Links

Jumlah website yang ditentukan di mesin pencari tertentu atau internet yang berisi link ke halaman tertentu. Istilah ini juga disebut sebagai "inbound links" atau "incoming 
links".

5. Bot

Singkatan untuk robot atau spider. Istilah ini untuk program perangkat lunak website yang mewadahi pengindeksan website oleh mesin pencari atau pemungutan alamat e-mail.

6. Cache

Sebuah snapshot dari halaman web yang memberitahukan rekam jejak penelusuran.

7. Cloaking

Tindakan penyajian informasi yang berbeda dari mesin pencari yang menjaring pengunjung untuk dapat melihat. Teknik ini merupakan salah satu teknik dari Black Hat SEO.

\section{Crawler}

Nama lain untuk laba-laba mesin pencari.

\section{Cross Linking}

Beberapa situs yang terhubung bersama-sama untuk meningkatkan popularitas link. Istilah ini juga disebut sebagai "interlinking".

10. Cascading Style Sheets (CSS)

Cara yang digunakan untuk memanipulasi dan mengelola desain dengan mudah dari format sebuah website.

11. Direktori

Website yang mendaftar situs-situs lain dan disusun dalam berbagai kategori. Editor menilai setiap situs web dan jika disetujui akan ditempatkan ke dalam kategori tertentu pada suatu direktori.

12. Deskripsi

Istilah ini biasanya memiliki dua kegunaan pada posisi mesin pencari, yakni dapat merujuk pada meta tag description yang merupakan baris kode di header halaman dan digunakan untuk menggambarkan tentang apa halaman tersebut atau dapat juga merujuk pada deskripsi dari situs apa yang akan dikirimkan ke webmaster.

13. Doorway Pages

Bagian ini digunakan dalam hubungan dengan pengalihan dan cloaking. Pada bagian ini dapat menemukan informasi lebih lanjut dengan Tactics SEO Black-Hat.

14. Gateway Pages

15. Google Bot

Istilah untuk jaring mesin pencari Google.

16. Head

Kode yang ada pada website. Namun, pada dasarnya tak terlihat oleh pengunjung. Kode ini meliputi judul, meta tag kata kunci, deskripsi meta tag, robot tag dan juga dapat berisi scripting dan informasi tambahan lainnya.

17. Hidden Text

Teks yang tak terlihat oleh mata manusia karena sudah diatur dengan warna yang sama 
MEDIASI Vol. 1 No. 2, Mei 2020

Dwi Mandasari Rahayu, Agung Budi Prasetyo

dengan latar belakang. Hal ini merupakan salah satu teknik dalam black head SEO.

18. Header

Pada dasarnya terdapat enam susunan tag mulai dari $\langle\mathrm{H} 1\rangle$ sampai $\langle\mathrm{H} 6\rangle$. Tag ini biasanya digunakan untuk memisahkan website menjadi bagian-bagian logis, yakni bertindak sebagai judul untuk berbagai bagian halaman. Hal ini umumnya isi header diberi bobot yang lebih tinggi dari standar isi karena muncul lebih menonjol pada halaman.

19. Inbound link

20. Keywords

Kata-kata yang digunakan untuk mengidentifikasi tema website.

21. Keyword Density

Persentase kata kunci atau frasa tertentu. Contohnya adalah 1 kata kunci dalam 100 kata halaman teks, sama artinya dengan kepadatan kata kunci $1 \%$.

22. Keyword Stuffing

Kata kunci pengisian mengarah pada praktik menambahkan kata kunci yang tidak perlu ke website untuk memimpin mesin pencari dalam mempertimbangkan halaman agar menjadi lebih relevan.

23. Link Popularity

24. Meta Tags

HTML digunakan dalam kode sumber untuk menyediakan konten dan situs informasi pada search engine spider.

25. Mirror

Mirror adalah situs duplikat yang hampir identik dengan halaman asli.

26. Optimasi Offsite

Metode untuk meningkatkan peringkat situs dengan memengaruhi hubungan dengan situs lain, terutama link yang ditemukan di website lain ke website sasaran.

27. Optimasi

Tuning situs atau website dengan tujuan akhir yang lebih tinggi untuk mencapai peringkat.

28. Outbound link

Fungsinya adalah untuk menghubungkan dari laman web satu ke web lain.

29. Page Rank

Alat Google untuk mengukur pentingnya laman web.

30. PPC (Pay-Per-Click)

Search engine yang beroperasi dengan cara pengisian situs per klik sehingga muncul lebih tinggi dalam peringkat.

31. Reciprocal Link

Dua situs bertukar link dengan menempatkan link ke satu sama lain di setiap situs.

32. Redirects

Sebuah taktik spam yang digunakan untuk mengarahkan pengunjung ke halaman yang 
MEDIASI Vol. 1 No. 2, Mei 2020

Dwi Mandasari Rahayu, Agung Budi Prasetyo

berbeda dari yang ditemukan pada hasil pencarian.

33. Robot

Sebuah nama yang diberikan untuk bot program spider/crawler yang bergerak mengumpulkan data dari laman web.

\section{METODE}

Teknik pengerjaan SEO dalam riset ini dibagi menjadi dua bagian, yaitu On Page dan Off Page. Menurut Davies (2013) dalam buku "SEO for Google in Fire Easy Steps", terdapat lima tahapan dalam optimasi SEO, yaitu:

1. On-Site SEO Basics

2. Optimalisasi Konten

3. Off-Site Optimization (Link Building)

4. Optimasi Media Sosial

5. Memantau website menggunakan Google Analytics

Lima tahapan tersebut didukung pula dengan SOP dalam optimalisasi konten artikel guna mendukung keberhasilan SEO. SOP tersebut merujuk dari teori Patil Swati P, Pawar B.V dan Patil Ajay (2013), yaitu sebagai berikut:

1. Menggunakan ALT tag pada gambar agar dapat di-crawling

2. Menggunakan Anchor text pada keywords di artikel

3. Artikel memiliki minimal 300 kata

4. Persentase keyword density $2 \%-8 \%$

5. Meletakkan keyword yang ingin dioptimasi pada URL

6. Melakukan optimasi keywords menggunakan tag header $\langle\mathrm{h} 1\rangle,\langle\mathrm{h} 2\rangle,\langle\mathrm{h} 3\rangle$, dan $\langle\mathrm{h} 4\rangle$

7. Tidak melakukan duplikasi konten dari situs lain

8. Memberikan judul yang baik dan menarik pada halaman

9. Keywords yang ingin dioptimasi harus terdapat pada judul artikel

10. Memiliki inbound link yang berkualitas

11. Melakukan optimasi secara on-site dari satu artikel ke artikel yang lain di laman web yang sama.

12. Melakukan update secara rutin dengan konten yang menarik

\section{HASIL DAN PEMBAHASAN}

Penelitian ini dijalankan dengan menggunakan alur kerja seperti yang terlihat pada bagan alir berikut ini. 


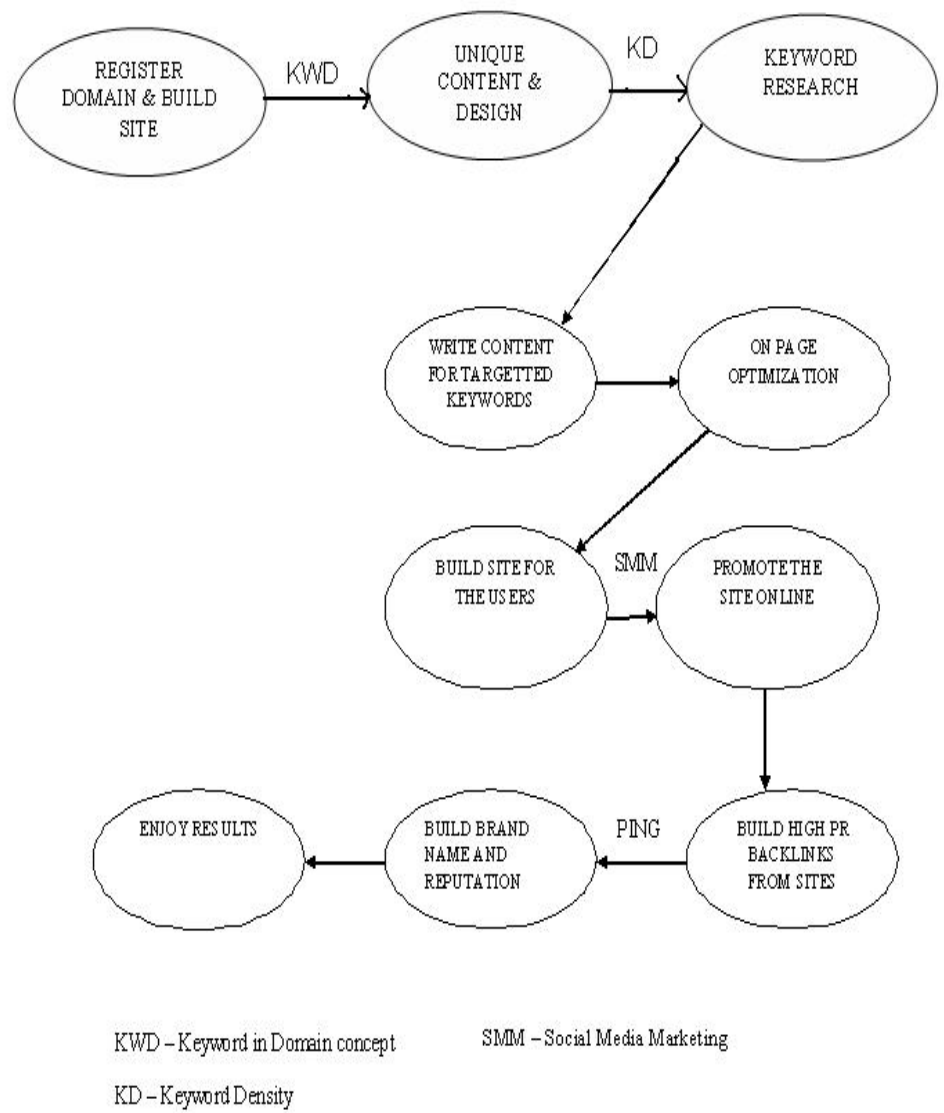

Sumber: Saravanakumar, Ramnath, Ranjitha \& Gokul (2012: 473) Gambar 1. Flowchart for Creating a Optimized Website

Dengan mengimplementasikan SEO untuk mencapai hasil dari pencarian, perlu melakukan update dengan algoritma mesin pencari yang berubah dari waktu ke waktu. Dengan demikian, perubahan-perubahan tersebut dapat mengindikasikan spam untuk crawler. Selain itu, yang ditekankan selanjutnya adalah mengikuti dasar rekomendasi dan membangun link dengan anchor text yang berbeda dari semua link seperti pengiriman artikel, link forum, situs ib 2.0, komentar blog, dan lain-lain untuk keragaman dalam struktur link.

Untuk mengimplementasikan riset tersebut dilakukan dua metode yakni SEO OnPage dan SEO Off-Page. Metode SEO On-Page merupakan pengaturan SEO yang dilakukan dari dalam laman web itu sendiri. Beberapa proses yang dilakukan dalam metode SEO OnPage meliputi: pengaturan nama domain, pengaturan judul laman web, pengaturan meta tag description dan keyword, pengaturan tag heading $(\mathrm{h} 1, \mathrm{~h} 2, \mathrm{~h} 3)$, pengaturan tag alt dan title pada gambar, internal link, permalink. Sementara itu, metode SEO Off-Page merupakan pengaturan SEO yang dilakukan dari luar laman web. Beberapa proses yang dilakukan dalam 
MEDIASI Vol. 1 No. 2, Mei 2020

Dwi Mandasari Rahayu, Agung Budi Prasetyo

metode SEO Off-Page meliputi: social network, blogging, forum posting, artikel posting, video, file [doc. pdf, dll], directory submission, online answer.

Pengaturan nama domain sesuai dengan nama institusi, yakni https://www.polimedia.ac.id. Berikut adalah hasil SEO score review dari https://www.woorank.com/:

woorank
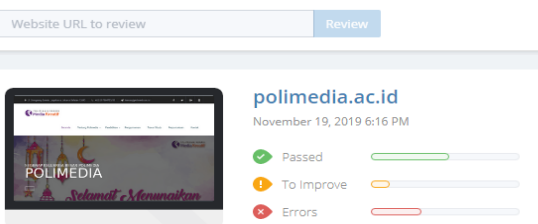

English $y \quad \log \ln$

\section{Free Trial}
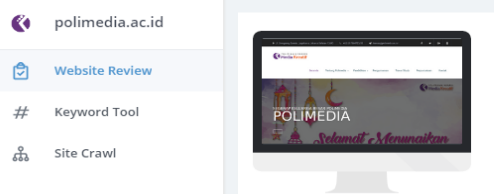

(3) To Im

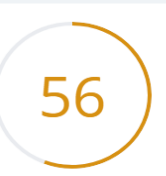

- Return to to

$\square$ Marketing

Site Cravi

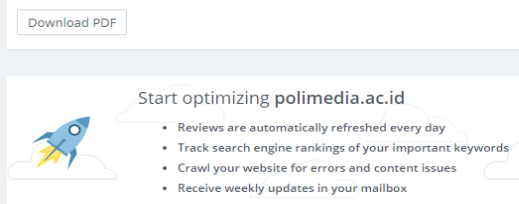

Share

ONPAGE

틀 content

Indexing

日 Mobile

Structured
Data

8. Security

(c) Performance

() Technologies

กิ Branding

(1) Domain

OFF-PAGE

\section{Gambar 2. SEO Score Woorank}

Secara branding laman Polimedia sudah memenuhi kaidah pemasaran menurut review Woorank dengan hasil seperti yang terlihat pada gambar 3 berikut ini.

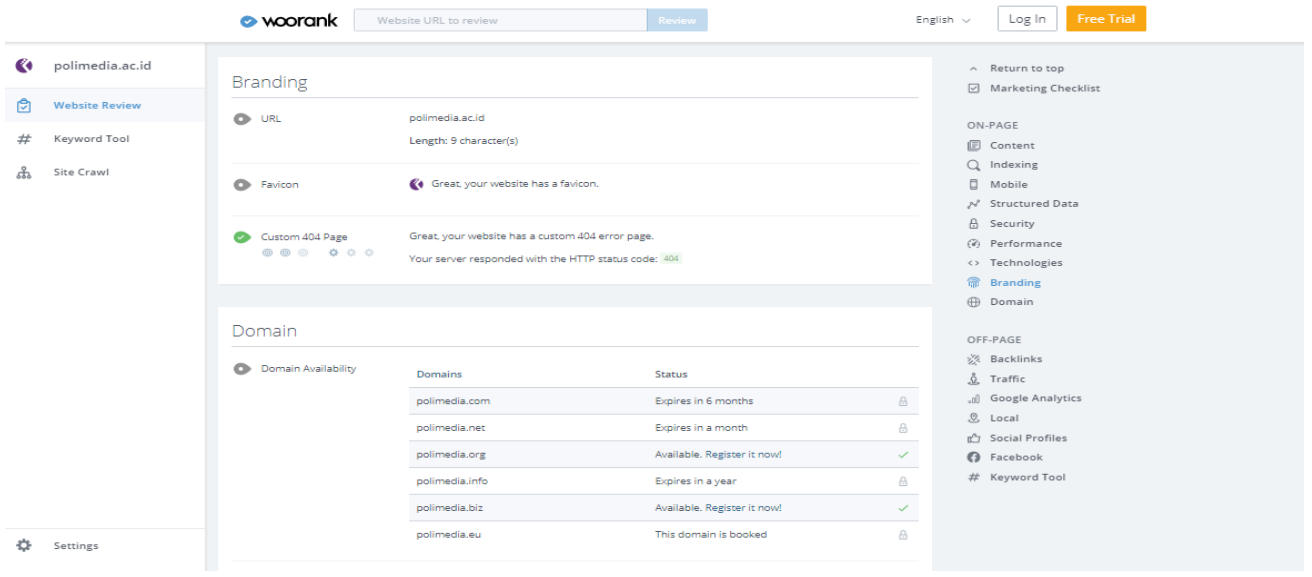

\section{Gambar 3. Branding}

Berdasarkan review tersebut diketahui bahwa URL sudah sesuai dengan nama institusi, faveicon (simbol ikon) menunjukkan logo (brand) dari institusi, mempunyai halaman pengalih jika terjadi error pada laman web.

Pengaturan tag heading [h2] juga sudah sesuai dengan kaidah pembuatan SEO dengan hasil seperti terlihat pada gambar 4 berikut ini. 
MEDIASI Vol. 1 No. 2, Mei 2020

Dwi Mandasari Rahayu, Agung Budi Prasetyo

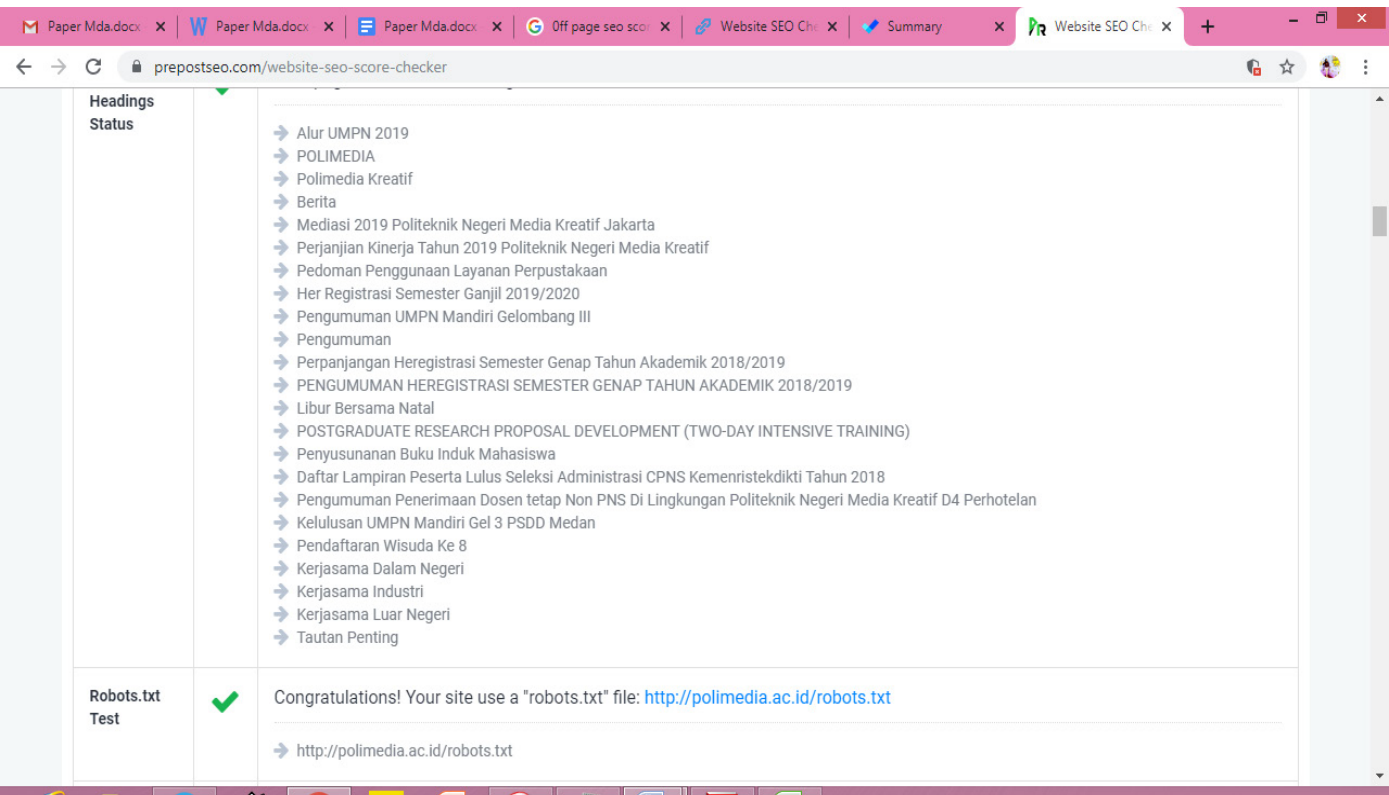

(e)

\section{Gambar 4. Heading 2 Title}

Polimedia juga mempunyai in-page link yang meningkat terdiri dari: internal link sebesar $64 \%$ dan eksternal link sebesar 36\%. Kondisi itu seperti yang terlihat pada gambar 5 di bawah ini.

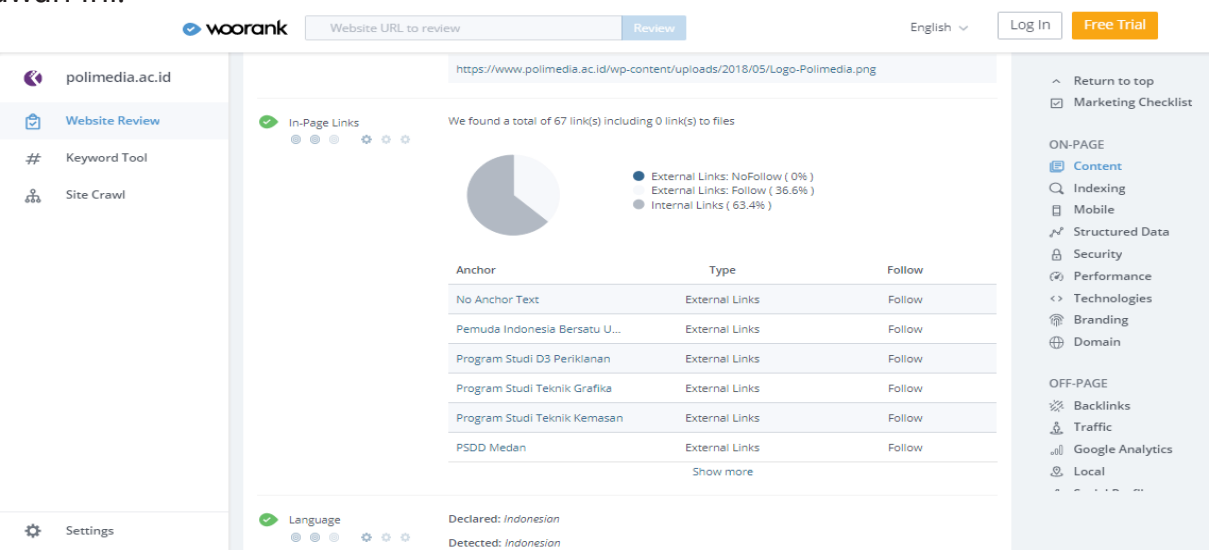

Gambar 5. In-Page Link

Berdasarkan temuan-temuan tersebut dapat dibahas lebih lanjut dengan analisis skor 56\% untuk nilai keseluruhan tingkat optimasi dinilai masih belum signifikan untuk meningkatkan target pemasaran, sehingga perlu peningkatan optimasi baik itu secara OnPage SEO maupun Off-Page SEO. 


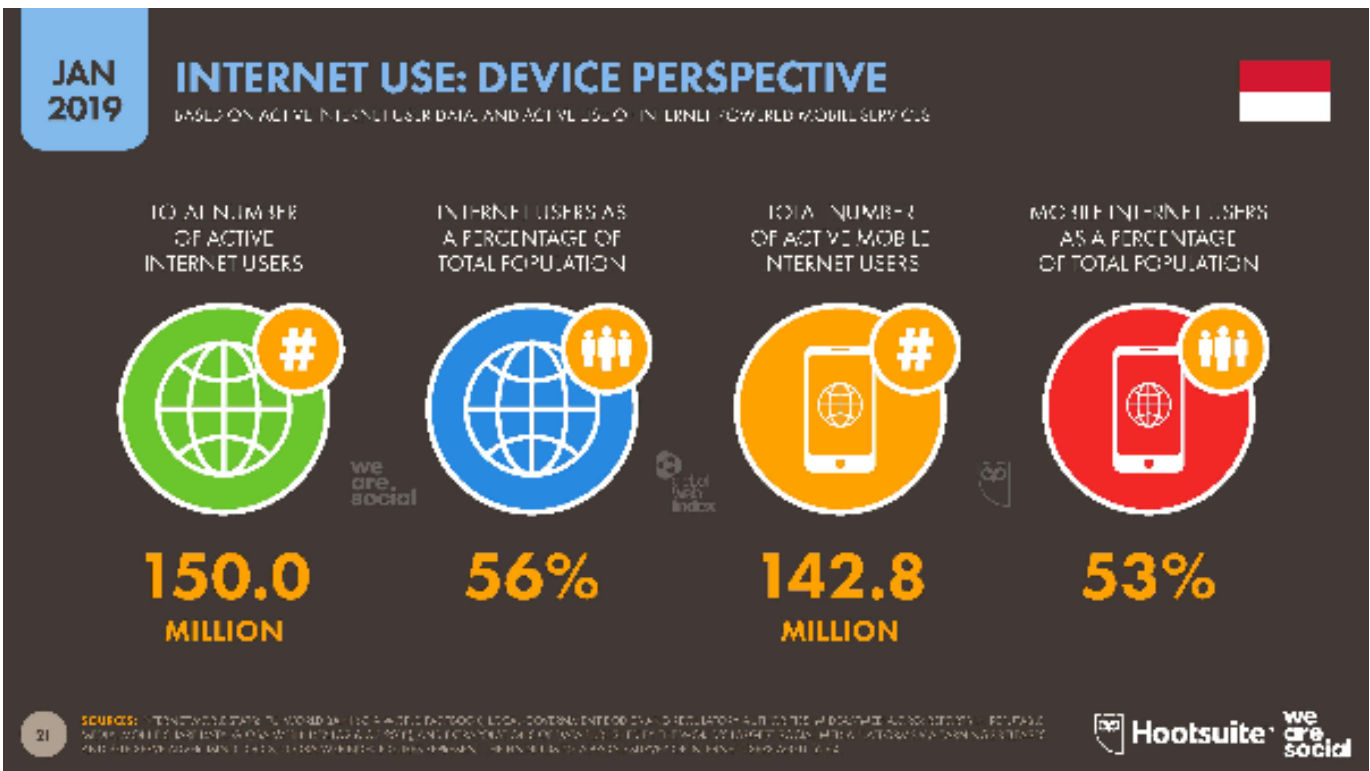

Gambar 6. Penetrasi Internet Indonesia

Jika kita mengacu pada data Internet World Statistic dinyatakan bahwa total pengguna internet di Indonesia pada 2019 ada 150 juta pengguna aktif atau sekitar 56\% dari total jumlah penduduk Indonesia. Dari sekian angka itu ada 142,8 juta pengguna yang mengakses melalui perangkat mobile, maka arah optimasinya adalah melalui Mobile Devices sebesar $53 \%$.

\section{SIMPULAN}

Kajian teknik SEO (Search Engine Optimization) sebagai strategi pemasaran melalui internet memberikan pandangan berdasarkan hasil penelitian bahwa rancangan laman web yang baik sesuai dengan kaidah SEO dapat meningkatkan trafik kunjungan dalam waktu tertentu. Target pengguna internet yang sesuai dengan target pemasaran juga akan meningkatkan branding.

\section{DAFTAR RUJUKAN}

Blythe, J. (2005). Essentials of Marketing 3rd Edition. Essex: Pearson Education Limited.

Davies, Mary. (2020). Beanstalk Internet Marketing. Beanstalkim. http://beanstalkim.com/ services/seo

Fang Chen-Ling dan Lie Ting. (2006). Assessment of Internet Marketing and Competitive Strategies for Leisure Farming Industry in Taiwan. Journal of American Academy of Business. ISSN 1540-1200, 8 (2), 296-300.

Hanieh Mirzaei, E. J. (2012). Differences of Traditional Marketing in Opposition to Electronic. Makalah disajikan dalam International Conference on Economics, Business, and 
Marketing Management, Singapore, 2012.

Jones, A. M. (2011). Internet Marketing: A Highly Practical Guide to Every Aspect of Internet Marketing. Textbook: University of Cape Town.

Kristen Purcell, J. B. (2012). Search Engine Use 2012. American: Pew Research Center.

MarkPlus. (2012). Profil Pengguna Internet Indonesia. Jakarta: APJII.

Nova Tri Cahyono, J. T. (2013). Penerapan Teknik SEO (Search Engine Optimization) pada Blog. Jurnal Teknologi Technoscientia, 6 (1), 80-88.

Report., W. T. (2010). International Telecommunication Report 2010: Monitoring The WSIS Targets. Geneva: World Telecommunication/ICT Development Report.

Samuel leong, N. M. (2012). Domain Bias in Web Search. Proceedings of the Fifth International Conference on Web Search and Data Mining, Seattle, USA, 2012. (page 413-422).

Tim Berners-Lee, R. C.-F. (1992). World-Wide Web: The Information Universe. Electronic Networking Journal, 2 (1), 52-58.

Vaughan, P. (2008). The Essential Step-by-Step Guide to Internet Marketing. Hubspot. http:// blog.hubspot.com/blog/tabid/6307/bid/16761/the-essential-step-by-step-guideto-internet-marketing-free-ebook.aspx. 